\title{
What are the impacts on temperate fish productivity of shoreline works activities? A systematic review protocol
}

\author{
Sommer Abdel-Fattah ${ }^{1 *}$ and Sarah Hasnain ${ }^{2}$
}

\begin{abstract}
Background: Shoreline works include any unnatural alteration or human intervention to coastal areas such as infilling, armouring, aquatic vegetation removal or planting, actions altering coastal processes, embayment creation, etc. The Fisheries Act requires that projects avoid causing serious harm to fish unless authorized by the Minister of Fisheries and Oceans Canada. This currently applies to work in or near water bodies that support or are part of a commercial, recreational or Aboriginal fishery. The Fisheries Protection Program, a decision-making body regulating the sustainability and ongoing productivity of these fisheries, utilizes various metrics of fish productivity to determine serious harm. The goal of this systematic review is to assess the type of shoreline alteration and their reported effects on fish productivity outcomes relevant to the temperate regions of Canada. The primary goal is to answer the question "how do the characteristics of shoreline works/alteration activities affect temperate fish productivity? "This review will assist Fisheries and Oceans Canada in determining future information needs, developing standards for evaluating serious harm, and providing an evidence base for decision making. Furthermore, this review will also result in a database that will provide access to information relevant for determining the impacts of shoreline alteration on fish communities.

Methods: We will conduct a systematic search using multiple online scientific and government databases as well as specialist sites to gather literature relevant to the temperate region of Canada that examines the impacts of shoreline alteration and development on fish productivity. We will consider studies globally, but will focus our research on those that include freshwater, or estuarine environments that have a coastal impact. Study data will be extracted and appraised for quality and compiled for a meta-analysis to be completed should the available data be adequate to do so. Relevant research outcomes will be evaluated by a range of measures used by authors to define productivity and its surrogates, including but not limited to fish yield, abundance, recruitment, body size, community index, species richness or diversity, and species density. Effect size and magnitude, frequency and duration data from the relevant studies will be extracted and assessed through a meta-analysis to quantify or estimate the overall effects of shoreline alteration and development types on fish productivity. The impact of habitat alteration magnitude (e.g. project size, project duration) and fish population and community characteristics (e.g. fish taxonomy, thermal or habitat preferences) on effect size will also be assessed using sub-group analyses.
\end{abstract}

Keywords: Coastal, Aquatic, Habitat alteration, Modification, Design, Restoration, Disturbance

\section{Background}

Shoreline works include any unnatural alteration or human intervention to nearshore areas such as infilling,

\footnotetext{
*Correspondence: abdelfs@mcmaster.ca

1 Bachelor Engineering and Technology Program, McMaster University,

1280 Main St. West, Hamilton, ON L8S 4L8, Canada

Full list of author information is available at the end of the article
}

armouring, aquatic vegetation removal or planting, or other actions that may alter nearshore or coastal processes. Fish and fish habitat could be affected by the alteration of their existing habitat and may include changes in the quality and quantity of fish habitats, habitat availability, water depth, velocity, water temperature, sedimentation, water quality, food resources, and competition for food and habitat. These changes could have serious 
implications for fish health and survival including species diversity; fish population distribution, fish population relative abundance, fish population biomass, sedimentation, stranding, and fish entrainment. Depending on the type of alteration, changes in fish movement and fish species population may be affected in the form of movement patterns and general life history parameters or fish productivity. Randall et al. [1] defined fish productivity as "the sustained yield of all component populations and species and their habitat which support and contribute to a fishery". It should be noted that this definition is best for large projects, while for smaller projects surrogates of productivity may be more appropriate. To address this issue, Bradford et al. [2] developed a framework for assessing productivity via its "components"; aspects of fish population productivity that may be altered by a change in conditions caused by a proposed project. In this framework, impacts on fish productivity are separated into five components: growth, individual performance, survival, migration, and reproduction. In addition, twenty-one Pathways of Effects (PoEs) link activities on the water or shoreline with a probable response of the environmental variables. Based on this framework, linkages can be made between the environmental impacts following an activity and their effects on fish and fish population production (known as state-productivity relationships). Some potential measures and surrogates of ongoing productivity of temperate fish species and their habitats include abundance, biodiversity, quantity of available habitat, and abundance [1,3]. Bradford et al. [2] define a component of productivity as "an aspect of fish population productivity that may be altered by a change in conditions caused by a proposed project". Understanding how shoreline changes will impact fish productivity is essential for decision support of shoreline works in nearshore areas.

In June 2012, the Government of Canada introduced amendments to the Fisheries Act that included substantive changes to the protection of Canadian fishes and fish habitats. Scientific advice is needed to support and inform the implementation of these policies through the Fisheries Protection Program (FPP) of Fisheries and Oceans Canada (DFO). FPP serves as a decision-making body for the sustainability and ongoing productivity of commercial, recreational and Aboriginal (CRA) fisheries with the goal to prevent serious harm to fish that included the destruction or permanent alteration to fish (Fisheries Act [4]). In this review, CRA fish are limited to "temperate" fish species to restrict the scope of the study. The amended Fisheries Act defines serious harm to fish as "the death of fish or any permanent alteration to, or destruction of, fish habitat", and allows the Minister of Fisheries and Oceans Canada to authorize a work, undertaking, or activity that causes serious harm to fish, if proposals are accepted after taking specified factors into account. Factors for Ministerial consideration in decision-making include: (a) the contribution of the relevant fish to the ongoing productivity of CRA fisheries; (b) fisheries management objectives; (c) whether there are measures and standards to avoid, mitigate or offset serious harm to fish that are part of a commercial, recreational or Aboriginal fishery, or that support such a fishery; and (d) the public interest. The new Fisheries Act introduces the need for metrics of productivity and methods to assess how a project may affect productivity. Projects that affect fish habitat can be classified into three types as those that: (1) reduce habitat quantity and carrying capacity; (2) affect habitat quality and fish vital rates and (3) impact at scales large enough to result in ecosystem transformation $[2,5,6]$.

Shifting from a habitat-based policy [7] to a fisheries-based approach has led to using productivity as a measure for assessing serious harm to fish [1, 2]. Fish productivity is an appropriate measure for assessing impacts of projects, works or activities on CRA fisheries, as ongoing productivity implies maintenance of ecosystem function and structure [1]. A change in a component of productivity is expected to have some effect on fish productivity in general depending on the interactions between components, and the magnitude and scale of the change [2]. Bradford et al. [2] also provide possible surrogates of productivity for each project type as defined by Randall et al. [1].

New amendments of Fisheries Act (2012) also put responsibility on developers to avoid and mitigate any "serious harm to fish" resulting from projects affecting aquatic habitat. In the event that serious harm cannot be completely avoided or mitigated during all stages of development, proponents must request authorization and develop a plan to counterbalance this harm using offsetting measures. It is therefore important to determine if coastal shoreline projects are a limiting factor of fish productivity and its components. In this review, the coastal area will not be defined by depth or distance from shore, but by the maximum extent of the project or alteration type itself.

Existing literature reviews on the impacts of shoreline alteration projects and their reported impacts on fish populations and communities have limited their scope to specific geographic areas, or specific alteration types, e.g. seawalls [8] or aquatic systems (e.g. north temperate lakes [9]). This review hopes to complement an existing systematic review protocol that was developed to assess impact of anthropogenic physical and structural habitat changes in nearshore areas on fish recruitment in temperate regions, but focused in Baltic relevant regions [10]. The review largely focused on marine and brackish 
systems or large lakes and focused on abundance of juveniles in nearshore fish communities before and after disturbance. To our knowledge, no synthesis of literature has examined impacts of shoreline projects of several components of fish health features across all life histories in estuarine and freshwater systems assessing a range of shoreline alteration types. Furthermore, none of these reviews provides quantitative measures of how physical and ecological characteristics, and project features influences fish productivity in nearshore areas. A quantitative evaluation of the impacts of shoreline alteration on fish productivity is necessary to identify future information and research needs, develop standards for evaluating potential serious harm and provide a knowledge base for DFO's future decision-making.

This systematic review aims to assess how shoreline works or alteration projects will affect the productivity of temperate fish. In this review, the types of shoreline alteration projects may include but are not necessarily limited to: hardening of shorelines, aquatic vegetation removal, change in depth through infilling, channel modification, riparian alteration, embayment creation vegetation planting/enhancement, artificial reefs, or other shoreline alterations designed to improve habitat through remediation, restoration or enhancement. When productivity is not defined or used within the literature, surrogates or components of productivity will be used in the evaluation [3]. During this review, the effects of impacts from more than one stressor from a single project as well as multiple projects in a localized area will need to be considered. Examples of potential measures and surrogates of productivity for CRA fishery species [3] include: production, catch, yield, biomass, abundance, density, recruitment, body size, biodiversity, species richness, mortality or survival, and somatic growth.

\section{Topic identification and stakeholder input}

Canada's Fisheries Act (2012) put renewed responsibility on developers to avoid and mitigate any "serious harm to fish" resulting from projects affecting aquatic habitats. Proponents must request authorization by submitting development plans to the Fisheries Protection Program and to demonstrate how offsetting measures will compensate for any serious harm. However, it is important that before and after development these impacts and offsets be monitored or assessed in order to understand the real and resultant effects on fish. This systematic review aims to gather the current evidence to understand what kinds of design options and shoreline alteration works most affect fish productivity either positively or negatively. Identifying if shoreline projects are affecting habitats and their productivity directly or indirectly will help inform the referral process and desired outcomes.
The topic and the scope of this systematic review were developed from consultations with an Advisory Team consisting of FPP, DFO Science, and the Ministry of Natural Resources and Forestry (OMNRF) staff. The Advisory Team also guided the focus of this review to ensure the primary and secondary questions were both answerable and relevant. The Advisory Team also reviewed the key search terms and aided in compiling a list of relevant terms related to productivity surrogates.

\section{Objectives}

This systematic review aims to assess the effect of shoreline alteration projects on fish productivity. However, we will restrict our review to studies assessing productivity $[3,11]$ of temperate fish; hereby referred to as "relevant species". Our objective is to identify the type, and strength of shoreline alteration effects on the productivity of relevant species. This review will cover existing studies conducted in all temperate aquatic ecosystems, largely estuarine and freshwater regions of the world because this study will be used to inform FPP policy.

\section{Primary question}

What are the effects of different types of shoreline alteration projects, works or activities on temperate fish productivity?

\section{Components of the primary question}

The primary study question can be broken down into the sub-components:

Subject (population) Fish species will be confined to those that are temperate species.

Exposure Shoreline alteration or shoreline works.

Comparator No exposure or alternative levels of exposure.

Outcomes Changes in fish productivity or surrogates of productivity such as abundance, biomass, growth, and others [3].

\section{Secondary questions}

Secondary questions were developed to support the overall goals and direct the potential analyses that may be performed from this review. The secondary questions related to shoreline alteration effects on productivity are:

1. Do fish productivity changes from shoreline alterations affect large lakes, small lakes, or lotic systems differently, and if so, how?

2. What are the major impacts from shoreline alterations to fish productivity?

3. How does fish utilization of shorelines change when comparing various shoreline protection designs versus the original natural shoreline? 


\section{Methods}

The systematic review will follow the direction on literature reviews established by the Collaboration for Environmental Evidence (CEE) in their Guidelines for Systematic Reviews in Environmental Management V4.2 March 2013.

\section{Searches}

As a check of the comprehensiveness of our search, 7 highly relevant articles were selected with consultation with our Advisory group as a known sample of reports or "benchmark studies" we would expect to see returned in our searches. The review team conducted a scoping exercise of potential search strings to test if they would return these reports within the results. A list of search terms was generated and divided into three components: population, intervention, and outcome (Table 1). These will be combined using Boolean operators "AND" and/or "Or".

\section{Abbreviated search}

When a complex search string is not accepted by the search engine, the search terms will be modified. The search terms will be recorded in the article databases in order to preserve all metadata associated with the search. Topics of importance include:

- Species richness/abundance/biomass.

- Mortality or survival.

- Quantity of available habitat.

- Barriers to movement.

- Predator-Prey availability/abundance/density (changes in community).

- Delayed/reduced reproduction.
- Habitat Suitability Index.

- Disturbance Index.

\section{Article type and format}

Articles will include project reporting, peer-reviewed journals, and grey literature. All article types will be equally researched and assessed to avoid biases.

No file types will be excluded from the search unless they require programming code to download or other hindrances to open, and in this case alternative files types will be requested from the authors. For the most part, digital forms of publications will be sought in order to maintain a folder of publications. We will use interlibrary loans subscriptions at McMaster University and Queens University to obtain access to any literature that may not be available in an online format.

\section{Computer settings}

The browsing history and cookies will be disabled on all computers used to conduct the search. The members of the Review Team will use "private mode" for web browsers to reduce the possibility of user-specific search results. The Review Team will disable any browsing preferences on their personal devices in order to reduce the possibility of previously visited sites or user-specific queries or location specific search results.

\section{Language}

Only the English language will be used during the search and supplied within the database. If any relevant article can be partially assessed through web-based translation (for example of only a title or abstract), it will be noted within the database, but not included in the analysis.

Table 1 Proposed search string for the execution of the searches

\begin{tabular}{|c|c|}
\hline & Search string \\
\hline \multirow[t]{2}{*}{ Population terms } & $\begin{array}{l}\text { (Aquatic OR Fresh water OR Freshwater OR Stream* OR Creek* OR Water* OR River* OR Lake* OR Reservoir* OR Pond* } \\
\text { OR Canal* OR Wetland* OR Channel* OR Beach* OR Nearshore OR Coast* OR Lentic OR Lotic OR Estuar*) AND (Fish*) }\end{array}$ \\
\hline & AND \\
\hline \multirow[t]{2}{*}{$\begin{array}{l}\text { Intervention terms (shoreline } \\
\text { alteration) }\end{array}$} & $\begin{array}{l}\text { (Restor* OR Rehabilit* OR Offset* OR Transplant* OR Enhanc* OR Excavat* OR Augment* OR Compensat* OR Improv* } \\
\text { OR Mitigat* OR Creat* OR Modif* OR Artificial* OR Riffle\$ OR Habitat* OR Protect* OR Construct* OR Plan* OR Armor* } \\
\text { OR armour* OR Design* OR Sediment* OR Disturb* OR Assess* OR Reduc* OR Remov* OR Qualit* OR Engineer* } \\
\text { OR stress* OR expose* OR Infill* OR harden* OR Vegetation Remov* OR Macrophyte Remo** OR Structure\$ OR } \\
\text { Depth OR Flow OR Barrier OR Embayment OR Impact* OR Habitat* OR Substrate* OR substrata OR substratum OR } \\
\text { Develop*) AND (*Shore*) }\end{array}$ \\
\hline & AND \\
\hline $\begin{array}{l}\text { Outcome terms (productivity } \\
\text { and productivity surrogates }\end{array}$ & $\begin{array}{l}\text { (Abundanc* OR Biomass OR Productiv* OR Densit* OR Surviv* OR Rate* OR Hatch* OR Spawn* OR Nest* OR Juvenile* } \\
\text { OR Redd\$ OR Embryo* OR Egg* OR Roe* OR Fry OR Chang* OR Product*OR Surplus OR Yield OR ICF Or Recruit* OR } \\
\text { Size OR Communit* OR Ecosystem* Function* OR Ecosystem\$ OR Richness OR Density OR CPUE or BPUE OR Mortal- } \\
\text { ity OR Surviv* OR Suitabilit* OR Displace* OR Load* OR Decompos*) }\end{array}$ \\
\hline
\end{tabular}

The asterisk is a wildcard and represents any characters (e.g., restor* includes restore, restores, restoring, restoration) while the dollar sign (\$) includes zero or one character (e.g., stream\$ includes stream and streams). Broad search terms such as "fish", "aquatic life", were included in an attempt to capture studies of every relevant species. Fish species will be confined to those described in Koops et al. [3] as effected relevant species considered under the defined commercial recreational and Aboriginal fisheries 


\section{Publication databases}

1. ISI Web of Science core collection-core collection includes: Science Citation Index Expanded, Social Sciences Citation Index, Arts and Humanities Citation Index, Fully Emerging Sources Citation Index, Book Citation Index, Conference Proceedings Citation Index; the subscription used will be from Queen's University and McMaster University.

2. Scopus-abstract and citation database of peerreviewed literature including journals, books and conference proceedings.

3. ProQuest Dissertations and Theses Global-International depository of graduate dissertations and theses.

4. Federal Science Library DFO Collection (formally known as Waves Fisheries and Oceans Canada)Canadian government books, reports, documents, conference proceedings and journal titles.

5. Science.gov-US Federal Science.

\section{Search engines}

Internet searches will be conducted using the following search engines: Google Custom International Governmental Organizations (IGO) (https://cse.google.com/ cse/home?cx $=006748068166572874491: 55$ ez0c3j3ey) and Google Custom Non-Governmental Organizations (NGO) search (https://cse.google.com/cse/home?cx= 012681683249965267634:q4g16p05-ao). For literature searches conducted through Google custom searches, the first 200 search results (sorted by relevance) for links or will be screened for relevance to our primary and secondary questions.

\section{Specialist websites}

Specialist organization websites listed below will be searched using full or modified search strings. Data from the first 50 search results will be extracted, screened for relevance, and searched for links or references to relevant publications, data and grey literature. The list of websites was narrowed to the following 14 organizations (Table 2). The search will consist of English websites only. The search organizations are largely those from Canada, the United States and some European countries due to the commonality of present fish species and relevance.

Reference sections of accepted articles and relevant reviews will also be searched to evaluate relevant titles, symposium papers, and other articles that have not been found using the search strategy. Authors of any literature not available online will be contacted to provide a copy of the document. The Advisory Team will be consulted for advice on new sources of information. If adjustments must be made to the search strategy these will be justified and documented in the final review.

\section{Other literature searches}

The Advisory Team will be consulted for recommendations of new sources of information or contacts. We will also seek out grey literature by sending out email solicitation to contacts of the authors and the advisory team.

\section{Search database}

All literature obtained through the course of the systematic review will be preserved in a digital form when possible in a separate appended folder. Once all sources are compiled to the satisfaction of the Review Team and Advisory Team, the individual databases will be exported

Table 2 List of specialist organizations and their web addresses which will be searched for relevant literature

\begin{tabular}{|c|c|}
\hline Specialist website name & Web address \\
\hline Centre for Ecology and Hydrology & https://www.ceh.ac.uk/ \\
\hline Centre for the Environment, Fisheries and Aquaculture Science & https://www.cefas.co.uk \\
\hline Commonwealth Scientific and Industrial Research Organization & https://www.csiro.au/ \\
\hline Department of the Environment, Food and Rural Affairs & $\begin{array}{l}\text { https://www.gov.uk/government/organisations/department-for-environ- } \\
\text { ment-food-rural-affairs }\end{array}$ \\
\hline Fisheries and Oceans Canada & http://www.dfo-mpo.gc.ca/index-eng.htm \\
\hline Fisheries Research Service & http://www.gov.scot/Topics/marine/Publications/FRS-Reports \\
\hline Food and Agriculture Organization of the United Nations & http://www.fao.org/home/en/ \\
\hline Natural Resources Canada & https://www.nrcan.gc.ca/home \\
\hline National Institute of Water and Atmospheric Research & https://www.niwa.co.nz/ \\
\hline Ontario Ministry of Natural Resources and Forests & https://www.ontario.ca/page/ministry-natural-resources-and-forestry \\
\hline Parks Canada & www.pc.gc.ca/eng/index.aspx \\
\hline The Nature Conservancy & https://www.nature.org/ \\
\hline United Nations Environment Programme & www.unep.org/ \\
\hline US Fish and Wildlife Service & https://www.fws.gov/ \\
\hline
\end{tabular}


into CADIMA (http://www.cadima.info/) in order to eliminate any repeated or duplicated files and filter by inclusion/exclusion criteria. This database will serve as an archive of all searched relevant literature.

\section{Article screening and study inclusion criteria}

The eligibility of the studies obtained by the aforementioned search for the final analysis will be assessed via a set of inclusion criteria at three successive levels: title, abstract and full-text. First, we will evaluate by title to remove citations spuriously returned by our search (repeated references for the same studies). At this stage, both participating reviewers will assess an identical subset of studies to evaluate whether both reviewers are consistent in their technique of assessment and screening; this is in lieu of the Kappa inter-rater agreement statistic that would be used in a multi-reviewer assessment. The number of studies evaluated will be $20 \%$ of total papers up to a maximum of 100 studies [11]. If reviewers are inconsistent in their assessment of study relevance (40\% disagreement), discrepancies will be discussed and the inclusion criteria will be clarified or revised to ensure that consistent methods are utilized by all authors. All remaining citations will be assessed on the relevance of their title based on the criteria outlined above. For citations with a relevant title, we assess the relevance of their abstract. Studies found to be relevant at the abstract level will be assessed at the full text level. During these two stages, authors will again perform the same independent assessment to check consistency. If it is unclear whether a study meets the inclusion criteria at an initial level of screening, it will be included for evaluation at the next level of the systematic review.

The database will include a summary of all screening decisions made including search terms, and reasons for exclusion. All literature excluded at the full text level will be included with the review, as per compliance CEE guidelines. Any literature that may be difficult to assess suitability for exclusion will be retained and, if necessary, discussed with the Advisory Team. Articles will first be assessed by reviewing the abstract to examine if the set criteria exist. Any article that does not have an abstract will be screened at the full text level. Only English-language literature will be included during the screening stage.

In order to decide whether we will include an article (or 'study' within an article) we will evaluate it against a set of criteria. Failure to meet one of these criteria results in exclusion of the study.

To be included, the study must be/address a:

1. Relevant subject We will consider studies that examine the combined effects of shoreline development and related stressors on fish and fish communities or components of productivity. Combined effects may include spatial and temporal confounding, and unjustified pooling of data across areas.

2. Relevant populations Fish species, fish communities, assemblages, and individual species assessed will be confined to those that are temperate species.

3. Relevant exposure (Impacts) Development, modification or continuous activity by humans that impacts the physical, chemical and/or biological structure(s) or process (es) in or around terrestrial or estuarine systems including but not limited to hardening of shorelines, aquatic vegetation removal, altering coastal processes, changing flow, change in depth, dredging and excavation, channel modification, riparian alteration, and other types of intervention that may include alterations designed to improve habitat.

4. Relevant comparator Experiments or observational studies comparing control versus altered sites (CI), comparing 'before' (prior to start of shoreline alteration project, works or activity) and 'after' (after the completion of shoreline alteration project, works or activity at the same location) (BA) or using a randomized control trial design (RCT). There may be instances where the comparison is to some other form of baseline (e.g. 'natural' vs. 'modified' ecosystem). Restoration activities where a different area serves as a compensated site for a degraded area will not be examined using a relevant comparator since the locations of before activity and after may be different geographic locations.

5. Relevant outcomes (response variables) We will focus on identifying studies containing outcomes related to five components of fish productivity: (1) changes related to growth, (2) changes related to survival, (3) changes related to individual performance, (4) changes related to migration and (5) changes related to reproduction. Therefore, we will include studies examining effects on the abundance of individual species and assemblages, measures of biodiversity (species richness etc.).

6. Sufficient data/information To be included in the meta-analysis, a study must present sufficient information. If there is some missing information or it is clear that appropriate data was collected but it is not presented in a way that allows us to extract it, we can email the study authors to see if they are willing to share the information. Publications included in the systematic review must contain the following: (1) replication level/sample size, (2) averages (arithmetic means) for relevant comparators and, (3) variance estimates (as standard deviation, standard error or 
confidence interval). Further evaluation will be made to ensure that the publications included closely follow the criteria regarding populations, outcomes and comparators outline below. Failure to meet any one criterion will result in exclusion from our analysis.

\section{Potential effect modifiers and reasons for heterogeneity}

Studies included in our analysis may vary in effect size due to differing physical, geological and chemical characteristics of the site and the biological and ecological characteristics of the fish populations and communities impacted by shoreline alteration projects. These study level factors contributing to variation in effect size will be regarded as potential effect moderators. For each of the five productivity outcome components, we will define the following moderators:

\section{Habitat/site moderators}

System type (Freshwater/Estuarine), or eco-region (Freshwater and Estuarine), latitude, longitude, Area of water body impacted, Area of shoreline alteration project, Duration of shoreline alteration project, Flow type (Laminar/Turbulent/Helical/Shear/None), Flow evenness (Consistent/Variable), Water temperature (Pre and Post alteration), Water body type [Arm/Reservoir/Bay/Canal/Channel/Cove/Basin/Stream/Delta/ Estuary/Harbour/Watershed/Lake/River/Pond/Wetland), Sediment type(Boulder (250 to $<4000 \mathrm{~mm}$ )/ Cobble $(64$ to $<250 \mathrm{~mm}) /$ Gravel $(2$ to $<64 \mathrm{~mm}) /$ Sand $(0.062$ to $<2 \mathrm{~mm}) / \mathrm{Silt}(0.004$ to $<0.062 \mathrm{~mm}) /$ Clay $(0.00024$ to $<0.004 \mathrm{~mm})$ ], Extent of emerged and submerged vegetation, Number of macrophyte species present.

\section{Population/community moderators}

Community type (Benthic/Pelagic/Both), Number of fish species present, Taxonomic family of fish species/populations of interest, Thermal preference guild of fish species/ populations of interest, Reproductive guild of the fish species/populations of interest.

\section{Data extraction strategy}

Each of the studies that make it through full text screening level will be classified and coded in the article database using a number of parameters including (but not limited to):

- Study setting-lab or field.

- Study design (BA/CI/BACI/RCT).

- Temporal extent of study as noted in study.

- Replication-replicated or un-replicated in time and/ or space?
- Confounding factors-present, not present, unclear, and whether they were accounted for in the study (e.g., stocking, chemical modifications).

- Use of (and number of) control and/or reference sites.

- Statistical methods used in assessment.

- Accounting for and/or identifying potential effect modifiers as described in data extraction.

The extracted information will be used to assess the shoreline alteration impact on productivity, and when sufficient, good quality data exist, the information will be used in a meta-analysis. The following information will be recorded for studies in the meta-analysis: ID, Reviewer, Full Citation, Citation, Authors, Year, Title, Publication Type, Objective, Country, State/Province, Waterbody name, Name of general area, Waterbody type, System Type, Habitat Type, Project Type/Work Type, Study design, Intervention/s category, Comparator's category, Outcome categories, Productivity impacts, Confounded impacts, Secondary moderators, Outcome metric, Sampling method, Sampling description, Population level assessment, Assessment time, Response, Species, Common name, Gaps, and Remarks.

If there are any disagreements on inclusion/exclusion of articles based on the criteria identified, the Advisory Team will be consulted.

For each study included in our analysis, outcome means, measures of variation (e.g., standard deviation, standard error, confidence intervals), and sample sizes will be extracted from text or tables. Data presented in graphs will be extracted using the image analysis software, Image J version $1.5 \mathrm{k} \mathrm{l}$. If it is not possible to decipher information from graphs, the main contact author will be contacted to obtain the missing information.

\section{Study quality assessment/critical appraisal}

Finally, the full text of the remaining studies will be evaluated for validity and inclusion in the meta-analysis. Assessing a study's quality is complex and there are several assessment methods to choose from [12]. Even if studies meet our inclusion criteria, they may vary in 'quality'. Similarly, field experiments are often going to be more realistic than lab studies. Studies that have passed the inclusion criteria will be evaluated for susceptibility to bias based on any of the following study parameters: design, sampling, data analysis and results. For each study, characteristics of study quality contributing to a "low" or "high" risk of bias will be rated, based on specific bias assessment criteria (Table 3). An overall risk of bias estimate for each study will be generated by dividing the number of "high" scores by the number of bias 
categories. Studies will be categorized as having high, medium or low bias based on the number of bias susceptibility factors present in each study. Studies categorized as high bias will be removed from further analysis for lack of quality and robustness. Many studies will contain a before and after assessment or pre and post intervention results that may contain data about ecosystem relationships and examine fish responses. These data will be extracted, and if possible before-after-control-impact (BACI) design ratios will be used through a Bayesian approach to assess impacts (see Data synthesis and presentation). Meta-data of all articles that make it to the full text screening level will be extracted from the included studies by the Review Team and will be recorded in a MS-Excel database that will be made available with the published systematic review, as additional supporting files. However, only those studies that meet the full criteria will be used in the analysis. The initial "baseline studies" of relevant literature will be used to refine the data extraction fields as needed.

\section{Data synthesis and presentation}

The ultimate goal of this review is to assess the impact that shoreline development has on fish productivity to better inform management decisions. A narrative synthesis of data from all articles included in the systematic review will be generated in the form of a report. The synthesis will compile results and data will be displayed in tables and figures when possible. We will collect means, sample sizes and variance estimators (standard deviation, standard error and confidence intervals (frequentist)/credible region (Bayesian)) from all relevant studies. Effect size estimates from individual studies will also be aggregated. If a sufficient number of studies contain effect size estimates, we will also perform subgroup analyses with the potential habitat and population/community modifiers provided earlier, to assess which of these moderators have the most influence on the effect of shoreline alteration project types on fish productivity. Effect size will be calculated using Hedges' g [13]. Hedges' g transforms all effect sizes to a common metric, allowing for comparison across data. This meta-analysis will summarize the magnitude of impacts caused by different shoreline alteration types as well as effects of moderators on these impacts by using mixed effect models with study as a random effect. Furthermore, the meta-analysis will allow for comparison and contrast of results from different studies and identify patterns among study results. A modified BACI design will be estimated as the mean difference between modified and control sites after the intervention minus the mean difference between modified and control sites before the intervention [14], or via an intervention (control - modified) $\times$ time (before-after) intervention term [15]. We will also identify spatial and temporal confounding, and unjustified pooling of data across multiple factors in order to identify which data are most relevant. The meta-data extracted from the articles included at the full text screening level will be provided. It is hoped that these results will be used by FPP to develop decision-making frameworks for assessing serious harm to temperate fish species.

Table 3 Study quality assessment criteria

\begin{tabular}{|c|c|c|}
\hline Study parameter & Characteristic & Bias assessment \\
\hline \multirow[t]{4}{*}{ Design } & Study type & Before-after-control-impact or RCT; comparator \\
\hline & Study timeframe & Post monitoring minimum 2 years \\
\hline & Intervention type & Intervention type well described and quantities specified \\
\hline & Methods & Methods well described and repeatable \\
\hline \multirow[t]{4}{*}{ Sampling } & Pre-construction inventory/assessment & Pre site assessment with habitat features well described \\
\hline & Random sampling & Randomized assignment of control \\
\hline & Species & Relevant temperate fish species \\
\hline & Temporal or spatial replication & Replicated in time and space \\
\hline \multirow[t]{3}{*}{ Data analysis } & Data clear and well described & Poor data quality/quantity or statistical analysis \\
\hline & Measurements of fish response & Specific data on fish response related to intervention \\
\hline & Pre and post construction results & Exposure impact clearly shown numerically \\
\hline \multirow[t]{4}{*}{ Results } & Outcomes & Outcomes clearly described and interpreted \\
\hline & Uncertainty & Uncertainty described \\
\hline & Bias & Bias reporting \\
\hline & Confounding factors & Confounding factors described if any \\
\hline
\end{tabular}




\section{Authors' contributions}

The manuscript was drafted by SA-F and SH. Both authors read and approved the final manuscript.

\section{Author details}

${ }^{1}$ Bachelor Engineering and Technology Program, McMaster University, 1280 Main St. West, Hamilton, ON L8S 4L8, Canada. ${ }^{2}$ Department of Biology, Kingston, Queens University, Biosciences Complex 116 Barrie St., Kingston, ON K7L 3N6, Canada.

\section{Acknowledgements}

The Advisory Team, consisting of Dave Gibson and Brent Valere, Susan Doka, and Karen Smokorowski from Fisheries and Oceans Canada and Dak DeKerckhove from the Ministry of Natural Resources and Forestry, provided feedback on the article.

\section{Competing interests}

The authors declare that they have no competing interests.

\section{Availability of data and materials}

Should the manuscript be accepted, the data supporting the results will be archived in an appropriate public repository and the data DOI will be included in the article.

Ethics approval and consent to participate Not applicable.

\section{Funding}

The study was supported by the Fisheries Protection Program, Fisheries and Oceans Canada.

\section{Publisher's Note}

Springer Nature remains neutral with regard to jurisdictional claims in published maps and institutional affiliations.

Received: 29 June 2017 Accepted: 27 October 2017

Published online: 22 December 2017

\section{References}

1. Randall RG, Bradford MJ, Clarke KD, Rice JC. A science-based interpretation of ongoing productivity of commercial, recreational or Aboriginal fisheries. Department of Fisheries and Oceans, Canadian Science Advisory Secretariat, Research Document 2012/112, Ottawa; 2013.

2. Bradford MJ, Randall RG, Smokorowski KS, Keatley B, Clarke KD. A framework for assessing fisheries productivity for the Fisheries Protection Program. Department of Fisheries and Oceans, Canadian Science Advisory Secretariat, Research Document 2013/067, Ottawa; 2014.
3. Koops MA, Koen-Alonso M, Smokorowski KE, Rice JC. A science-based interpretation and framework for considering the contribution of the relevant fish to the ongoing productivity of commercial, recreational or Aboriginal fishes. DFO Can Sci Advis Sec Res Doc. 2013;2012(141):iii +28.

4. Government of Canada 2015 Fisheries Act. Available lawslois.justice. gc.ca/PDF/F-14.pdf (May 2015). 2014

5. DFO. A science-based framework for assessing changes in productivity, within the context of the amended Fisheries Act. DFO Can Sci Advis Sec Sci Advis Rep. 2013; 2013/071

6. DFO. Framework for assessing the ecological flow requirements to support fisheries in Canada. DFO Can Sci Advis Sec Sci Advis Rep. 2013b; 2013/017.

7. DFO. Policy for the management of fish habitat. Ottawa: Department of Fisheries and Oceans, Communications Directorate; 1986.

8. Chapman MG, Underwood AJ. Evaluation of ecological engineering of "armoured" shorelines to improve their value as habitat. J Exp Mar Biol Ecol. 2011;400(1-2):302-13. https://doi.org/10.1016/j.jembe.2011.02.025.

9. Jennings MJ, Bozek MA, Hatzenbeler GR, Emmons EE, Staggs MD. cumulative effects of incremental shoreline habitat modification on fish assemblages in North Temperate Lakes. North Am J Fish Manag. 1999;19(1):18-27

10. Macura B, Lönnstedt $O$, Byström P, Airoldi L, Eriksson BK, Rudstam L, Støttrup J. How is fish recruitment affected by anthropogenic habitat change in shallow nearshore areas in temperate systems? A systematic review protocol. Environ Evid. 2016;5:10. https://doi.org/10.1186/ s13750-13016-10061-z

11. Kenchington E, Duplisea DE, Curtis JMR, Rice JC, Bundy A, Koen-Alonso M, Doka SE. Identification of species and habitats that support commercial, recreational or aboriginal fisheries in Canada. Department of Fisheries and Oceans, Canadian Science Advisory Secretariat, Research Document 2012/110, Ottawa; 2013

12. Wells K, Littell JH. Study quality assessment in systematic reviews of research on intervention effects. Res Soc Work Pract. 2009;19:52-62.

13. Hedges LV, Pigott TD. The power of statistical tests for moderators in meta-analysis. Psychol Methods. 2004;9(4):426-45. https://doi. org/10.1037/1082-989X.9.4.426.

14. Bence JR, Stewart-Oaten A, Schroeter SC. Estimating the size of an effect from a before-after-control-impact paired series design. In: Schmitt RJ, Osenberg CW, editors. Detecting ecological impacts: concepts and applications in coastal habitats. San Diego: Academic Press; 1996.

15. Popescu VD, de Valpine P, Tempel D, Peery MZ. Estimating population impacts via dynamic occupancy analysis of before-after control-impact studies. Ecol Appl. 2012;22:1389-404. https://doi.org/10.1890/11-1669.1.

\section{Submit your next manuscript to BioMed Central} and we will help you at every step:

- We accept pre-submission inquiries

- Our selector tool helps you to find the most relevant journal

- We provide round the clock customer support

- Convenient online submission

- Thorough peer review

- Inclusion in PubMed and all major indexing services

- Maximum visibility for your research

Submit your manuscript at www.biomedcentral com/submit 